\title{
Chemo-thermal Treatment of Tribulus tresstris to Enhance Its Sequestering Potential for Adsorption of Some Heavy Metals from Aqueous Media: Kinetic and Thermodynamic Study
}

\author{
Muhammad Ashraf Shaheen ${ }^{1 *}$, Nusrat Bibi ${ }^{1}$, Tahir Mehmood ${ }^{1}$, Abdul Karim ${ }^{1}$, \\ Mudassir Iqbal ${ }^{2}$ and Robina Farooq ${ }^{3}$ \\ ${ }^{1}$ Department of Chemistry, University of Sargodha, Sargodha-40100, Pakistan. \\ ${ }^{2}$ Department of Chemistry, School of Natural Sciences, National University of Sciences and Technology (NUST), H-12, \\ Islamabad-44000, Pakistan. \\ ${ }^{3}$ Department of Chemical Engineering, COMSATS Institute of Information Technology, Lahore-5400, Pakistan. \\ *Corresponding Author Email: mashaheen@uos.edu.pk \\ Received 10 May 2016, Revised 17 August 2016, Accepted 18 August 2016
}

\begin{abstract}
The plant based renewable biosorbents have extensively been investigated for removing water pollutants. The present study describes the sequestering of metal ions by exploiting a low cost biomaterial derived from Tribulus tresstris as sorbent. The batch equilibrium studies have been carried out both with raw and chemically/thermally treated biomaterial as a function of $\mathrm{pH}$, contact time, shaking speed and shaking time to decide the effectiveness of biosorbent. The sorbent was activated chemically by utilizing $0.1 \mathrm{M} \mathrm{HCl}$ and $0.1 \mathrm{M} \mathrm{K}_{2} \mathrm{CO}_{3}$. A close muffle furnace was used for thermal treatment of the sorbent. The adsorption capacity was enhanced to $25 \%$ by thermal treatment and $54 \%$ by chemical treatment because of increase in pore volume and surface area. The greatest sorption was found for particle size of $200 \mu \mathrm{m}$ with a $0.5 \mathrm{~g}$ dosage at $\mathrm{pH} 6$ for $20 \mathrm{~min}$ at shaking speed $100 \mathrm{rpm}$. The FT-IR and SEM study was performed to discover the adsorption capacity of various functional groups and their binding mechanism. The adsorption data demonstrates that Langmuir, Freundlich and Dubinin-Radushkevich isotherm models were very much fitted to describe the adsorption behavior.
\end{abstract}

Keywords: Biosorption, Metal ions, Tribulus tresstris, Freundlich, Langmuir and DubininRadushkevich isotherms.

\section{Introduction}

Metallic species discharged to our ecosystem by different mechanical and innovative exercises of individuals and industries enter into food chain and cause irreparable continuous damage to natural ecosystems. Aside from scattered wellsprings of metals, expansive convergences of heavy metals enter in the environment from industrial activities due to inefficiencies built in technological activities. Life of individuals in addition to animals is being antagonistically influenced by the exceptionally harmful pollutants [1]. Today the major ecological pollutants are heavy metals (Co, $\mathrm{Hg}, \mathrm{Zn}, \mathrm{Cr}, \mathrm{Pb}, \mathrm{As}, \mathrm{Cu}, \mathrm{Ni}, \mathrm{Cd}$, and $\mathrm{Sn}$ ), and radioactive metals (Am, $\mathrm{U}, \mathrm{Th}, \mathrm{Ra})$ [2]. Various ventures like mining, refining, metal electroplating, manures and pesticides enterprises release substantial metals containing waste to ecosphere. Other critical sources of such kind of heavy metal wastes are photography, electrolysis, leather industries and nuclear installations. These metals are polluting the environment and posing a direct danger to human well being. The presence of toxic 
metals in the aqueous media above the tolerance levels is responsible for accumulative poisoning cancer, and brain damage. The compounds of lead are very toxic to humans and cause adverse health effects such as anemia, encephalopathy, hepatitis, and nephritic syndrome. Hence it is essential to remove these metal ions from wastewater before being discharged into an aquatic environment [3]. There are various conventional methods like precipitation, oxidation reduction, ion exchange, filtration, electro chemical processes, evaporation, reverse osmosis and membrane separation for this purpose. However, these methods are considered to have several disadvantages such as low selectivity, high cost, incomplete separation, high energy consumption and generation of toxic byproducts. The problems can be overcome by bio-sorption of metal ions on selected bio-sorbents. In this way, expulsion of these metals from wastewater is more efficient and economical. Bio-sorption of heavy metals is not just single mechanism based anyway it is influenced by several mechanisms that differ qualitatively and quantitatively according to the species used and their processing. A large number of bio-materials have been investigated to remove pollutants from aqueous media [4].

The sorption relies on the presence of various types of functional groups such as $-\mathrm{NH}_{2}$, $\mathrm{OH},-\mathrm{COOH},-\mathrm{CONH}_{2}$, $-\mathrm{SH}$ which are available in bio-sorbent for sequestering the overwhelming metal ions [5, 6]. In any case, the presence of such useful groups sometime does not ensure their availability for sorption, might be because of steric hindrance or conformational \%. The current study deals with investigation of the bio-sorption potential of Tribulus tresstris as bio-sorbent because it is wide spread plant and cheap.

\section{Materials and Methods Preparation of biosorbent}

Tribulus tresstris (TT) was collected from the vicinity of Sargodha, Punjab, Pakistan and was authenticated in the Department of Botany, University of Sargodha. The plants were washed with distilled water for removal of various impurities, followed by drying at $110^{\circ} \mathrm{C}$. The dried plant material was crushed and sieved to achieve particles of different sizes, i.e. 50, 100 and $200 \mu \mathrm{m}$.

\section{Chemical treatment of tribulus tresstris (CATT)}

The $10 \mathrm{~g}$ sample of uniform particle size was mixed with $20 \mathrm{~mL} 0.1 \mathrm{M} \mathrm{HCl}$ and filtered. Then sorbent was treated with $0.1 \mathrm{M} \mathrm{K}_{2} \mathrm{CO}_{3}$ solutions and finally repeatedly washed with distilled water to remove residual $\mathrm{HCl}$ and $\mathrm{K}_{2} \mathrm{CO}_{3}$. The neutralized sample was dried and stored for further use.

\section{Thermal treatment of tribulus tresstris (TATT)}

The thermal activation of samples was performed utilizing Closed Muffle furnace (Phoenix, Sheffield, England 1983) at temperature extending from $100-200{ }^{\circ} \mathrm{C}$ and heating rate of 10 ${ }^{\circ} \mathrm{C} / \mathrm{min}$ under nitrogen stream of $500 \mathrm{~mL} / \mathrm{min}$ for 5 $\mathrm{h}$ to increase the surface area of biosorbent.

\section{Scanning electron microscopy (SEM)}

By focusing a light energy of electron, a variety of signals are produced at the surface of solid sample. The SEM image gives data about morphology/composition, compound structure and crystalline nature of sample.

\section{Fourier transform infrared (FTIR) spectroscopy}

IR spectra of raw and treated bio-sorbent sample were recorded by $\mathrm{KBr}$ pellets technique using FT-IR spectrophotometer (prestige 21 Shimadzu). A significant change in the intensity and frequency of the functional groups on adsorbent surface was observed by FT-IR analysis of raw and activated samples [Fig.1-3]. This technique is a fast and non-destructive for identification of molecules using very small amount of sample [7].

\section{Analysis of metal ions}

AAS (Atomic Absorption Spectrometer, AA-6300 SHIMADZU) was used to analyze the metal ions in the solution. The concentration of metal ions was determined by their $\lambda$ max values prior and then afterward each addition of biosorbent. For a typical metal ion, the light source utilized was a hollow cathode lamp with their current value $15 \mathrm{Ma}$. The analyses for each metal cation was carried out in triplicate and mean qualities were adjusted. 
Results and Discussion

FTIR analysis of raw TT CATT and TATT

FT-IR spectrum of raw TT indicates that the structure of TT is relatively complex due to presence of several functionalities. The FT-IR spectra of raw TT and activated TT are shown in Fig.1-3. FT-IR spectra of raw TT and CATT are not much different which shows that treating biomass with mild acids does not induce significant changes in surface structure.

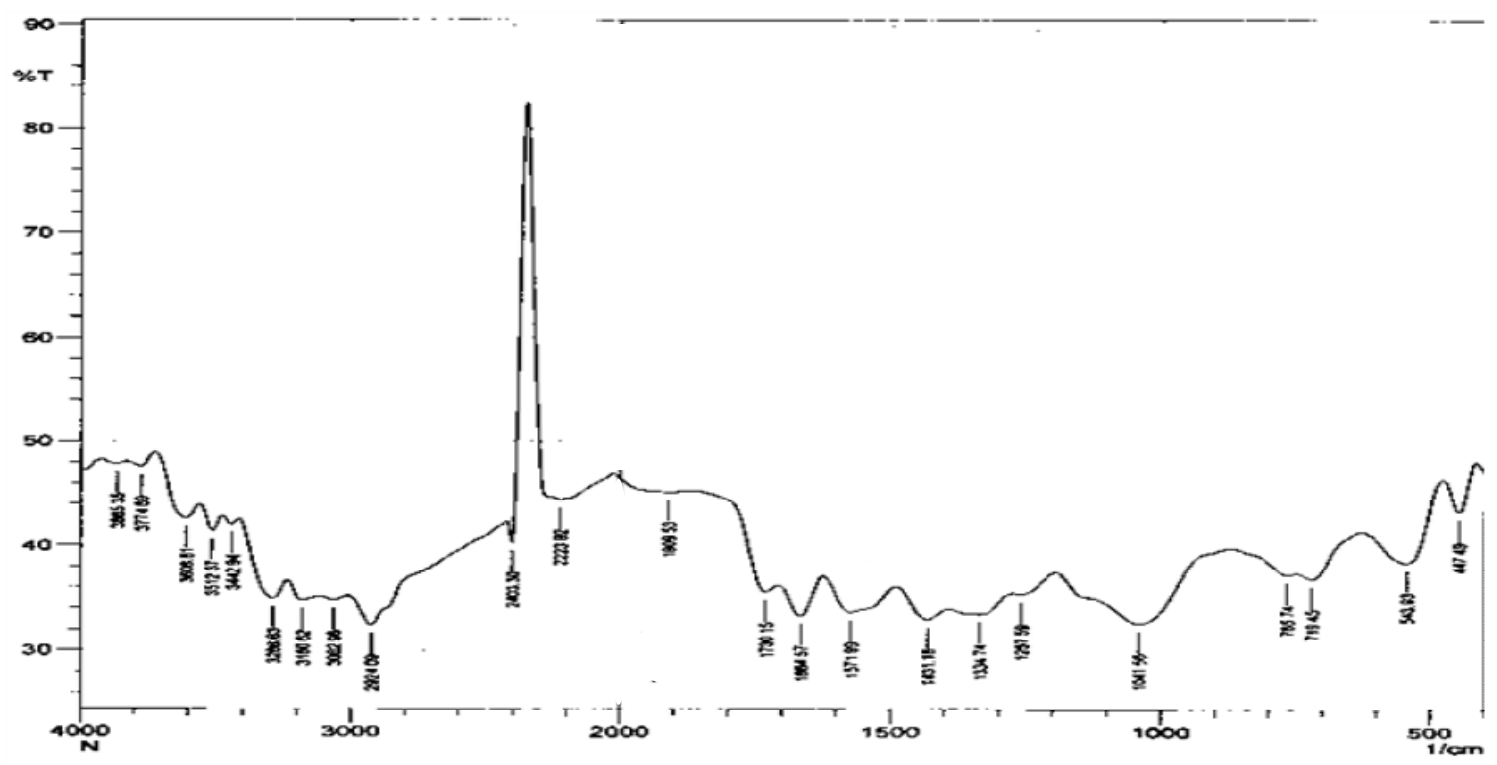

Figure 1. FT-IR Spectrum of Raw TT

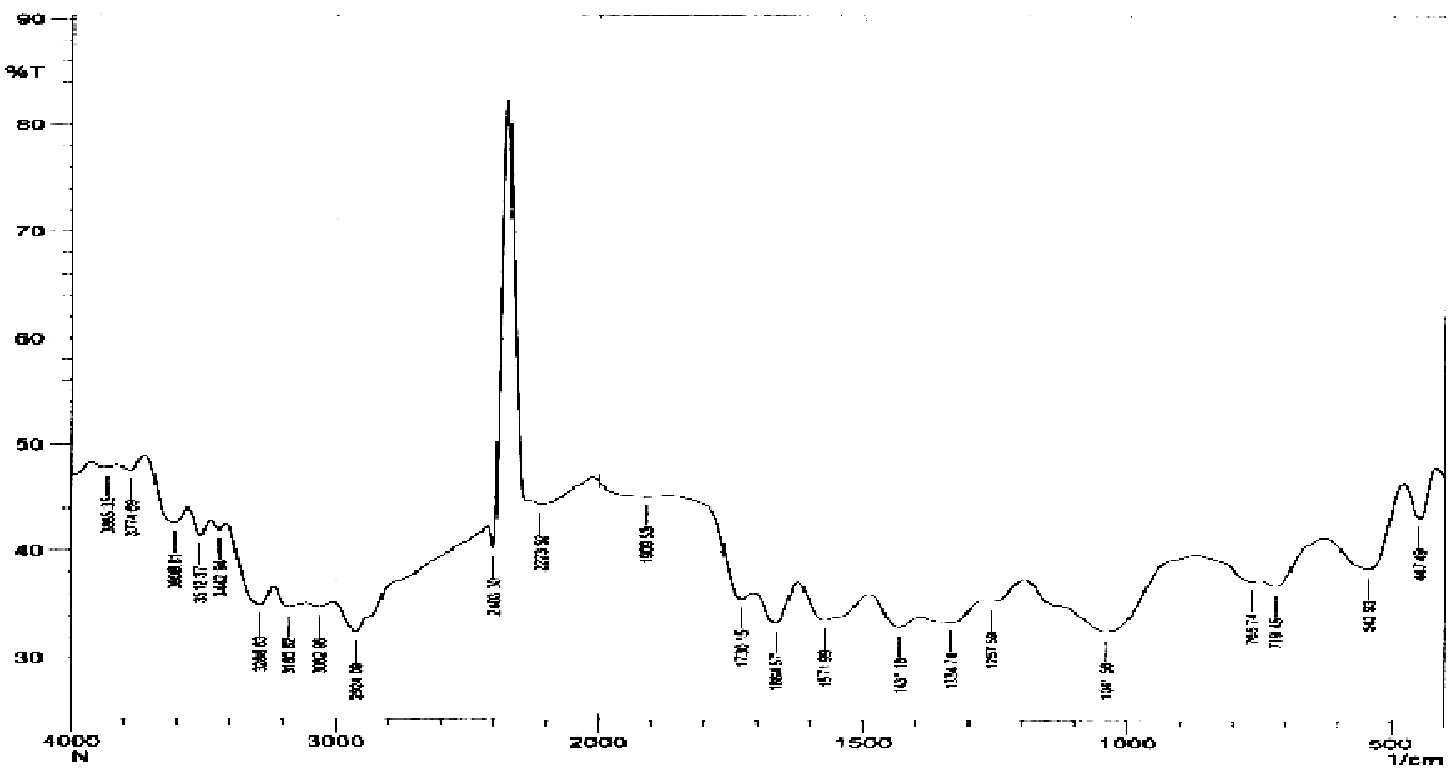

Figure 2. FT-IR spectrum of CATT 


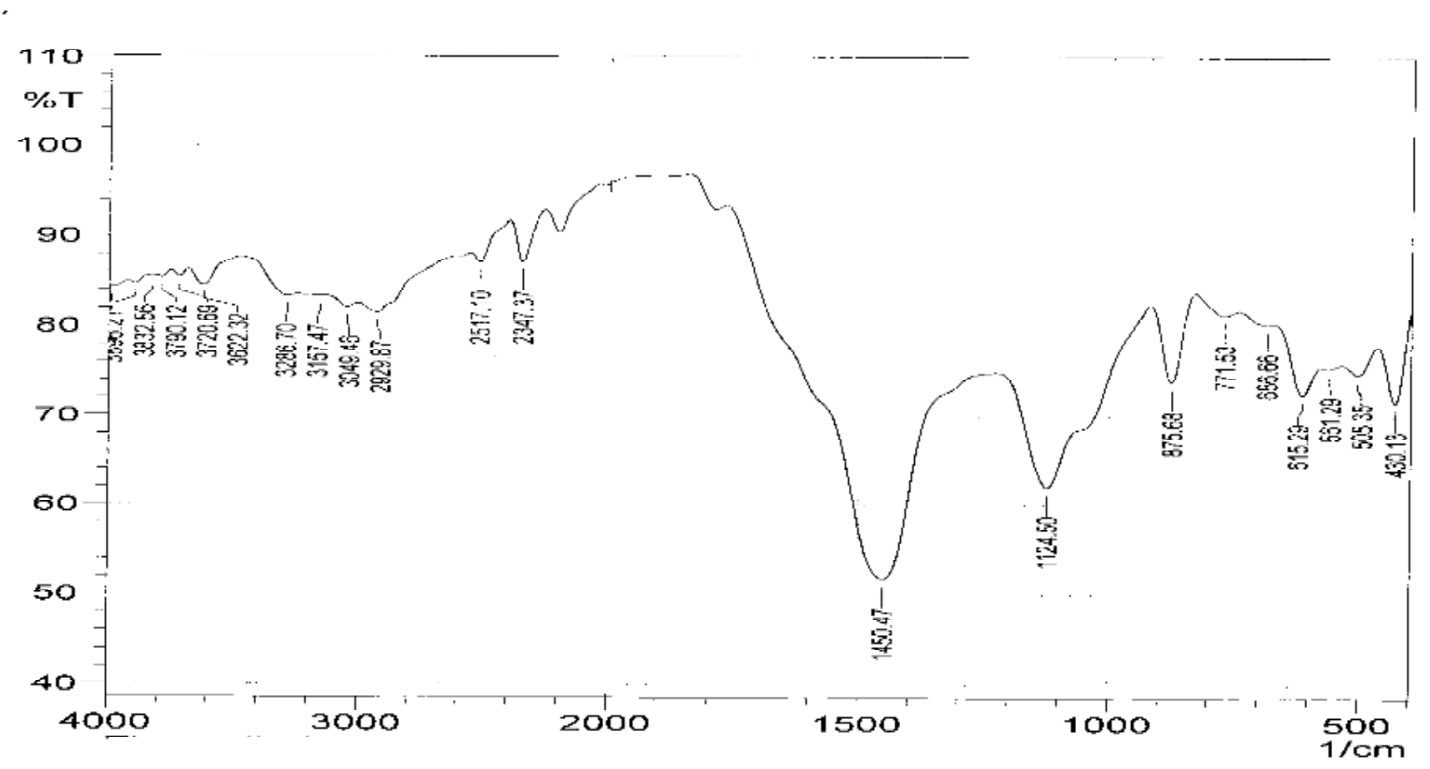

Figure 3. FT-IR spectrum of TATT

A peak around $3296.35 \mathrm{~cm}^{-1}$ in raw TT, indicating free and hydrogen bonded $-\mathrm{OH}$ functional groups normally found in cellulose. This shifting of peak in activated sample to $3290.56 \mathrm{~cm}^{-}$ ${ }^{1}$ shows deformity in the structure of $-\mathrm{OH}$ groups more suitable for adsorption (Table 2). The \% peak at $3057.17 \mathrm{~cm}^{-1}$ in raw sample, can be weak stretching to stretched aromatic $=\mathrm{C}-\mathrm{H}$, and $\mathrm{C}=\mathrm{C}$ groups. However, it is shifted to $3037.89 \mathrm{~cm}^{-1}$ in activated samples which can be attributed to deformation in structure, better for adsorption. In thermally treated samples, these peaks become weaker and shifted to $3049.46 \mathrm{~cm}^{-1}$ attributed to deformation however; lesser as compared to chemically activated peak at $2918.30 \mathrm{~cm}^{-1}$, indicates $-\mathrm{C}-\mathrm{H}$ stretching of alkanes for methylene or methyl groups while it's appearance at 2916.37 $\mathrm{cm}^{-1}$ and $2920.23 \mathrm{~cm}^{-1}$ in chemically and thermally activated samples respectively, suggesting minute changes.

The $\mathrm{C}=\mathrm{O}$ peak is visible around 1734.01 $\mathrm{cm}^{-1} \mathrm{can}$ be attributed to lignin aromatic groups with its shift to $1674.21 \mathrm{~cm}^{-1}$ in CATT sample which might be due to conjugation in the carbonyl functionalities. This conjugation may be due to adsorption in CATT sample.

The peaks around $1039.63 \mathrm{~cm}^{-1}$ and $1029.99 \mathrm{~cm}^{-1}$ indicate silyl ether linkage ( $\mathrm{Si}-\mathrm{O}-\mathrm{Si}$ ) in raw as well as CATT sample, while appearance of peak at $1103.28 \mathrm{~cm}^{-1}$ can be assigned to Si-O-C linkage. More prominent peaks are seen in raw sample as compared to activated sample, as adsorption potential might have been reduced in untreated sample due to strong vibrational frequencies (Table 2).

Table 2. Absorbance study of treated and untreated samples of TT.

\begin{tabular}{l|c|c|c|c|c|c}
\hline Adsorbent & $-\mathbf{O H}$ & $\begin{array}{c}\text { C=C, } \\
=\mathbf{C}-\mathbf{H}\end{array}$ & $-\mathbf{C - H}$ & $\mathbf{C}=\mathbf{O}$ & Si-O-Si & Si-O-C \\
\hline Raw TT & 3296.35 & 3057.17 & 2918.30 & 1734.01 & 1039.63 & ------- \\
CATT & 356290 & 3037.89 & 2916.37 & 1674.21 & 1029.99 & 1103.28 \\
TATT & 3288.63 & 3049.46 & 2920.23 & ----- & ------- & 1104.29 \\
\hline
\end{tabular}

\section{Scanning electron microscopy (SEM)}

The SEM pictures of raw and treated sample are shown in Fig. 4-5. An expansion in pore volume was seen in activated material. An increase in the percentage of activated carbon was found in treated samples being best wellspring of bio-sorption. This study is useful for investigating the metal binding to sample. It actually decides the change that happens in surface morphology. After metal binding, changes happen in cell wall composition which gives best information about the distribution of various elements on the sample surface. This system is likewise utilized for qualitative estimation of surface structure [8]. 

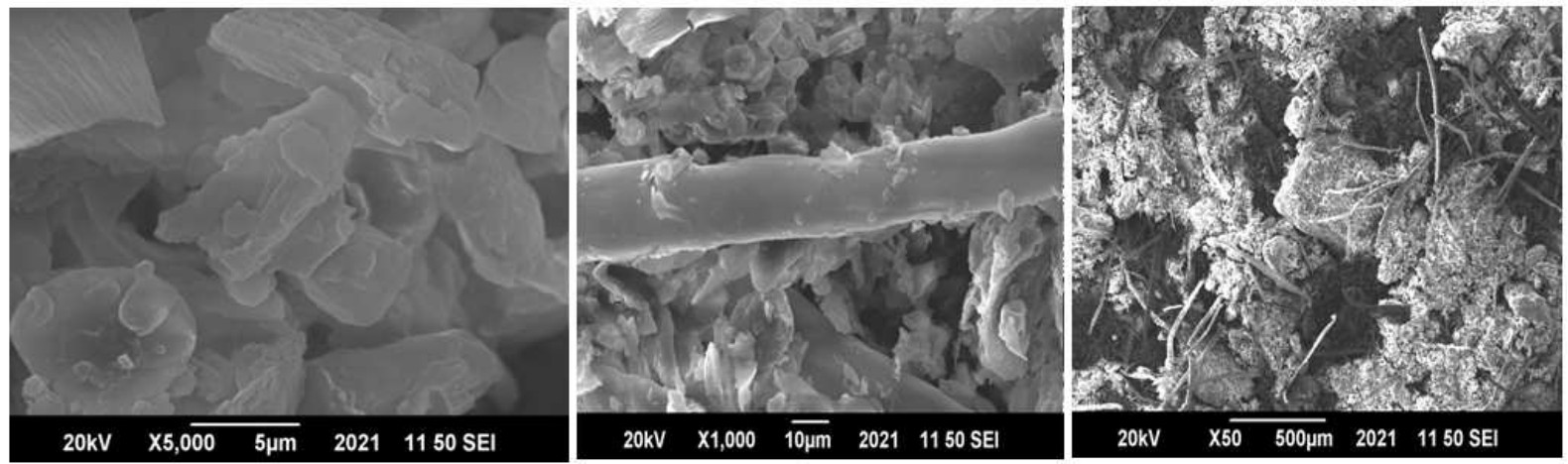

Figure 4. SEM images of raw $\mathrm{TT}(\mathrm{L} \rightarrow \mathrm{R})$ at 50 and 100 and $200 \mu \mathrm{m}$
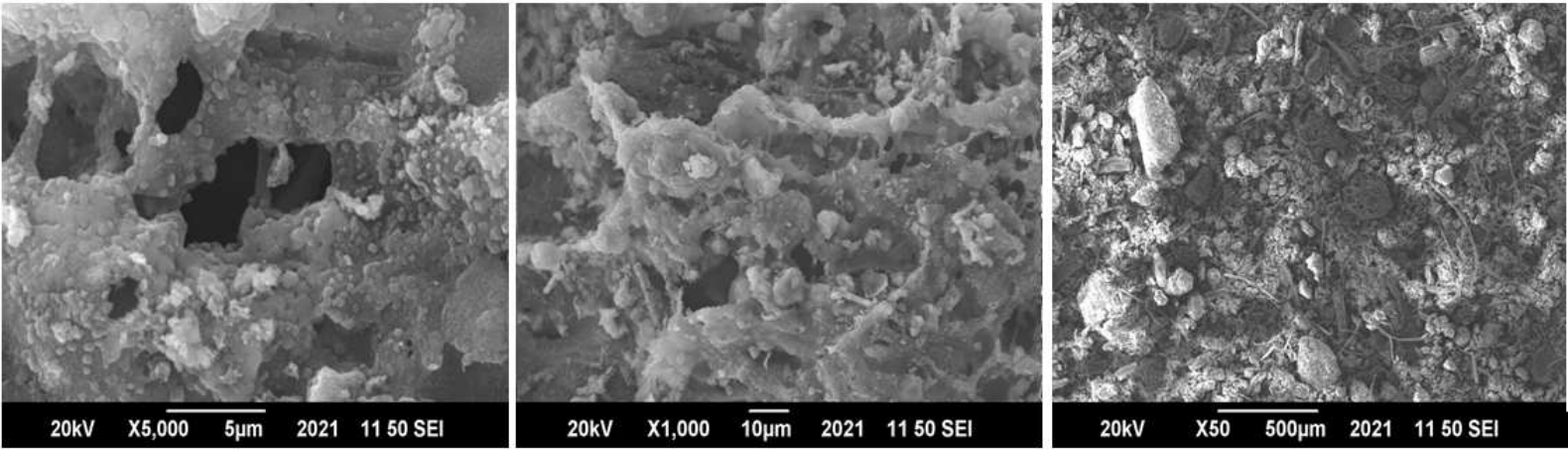

Figure 5. SEM images of TATT $(L \rightarrow R)$ at 50, 100 and $200 \mu \mathrm{m}$

\section{Measurement of porosity}

The pore capacity of sample was determined by centrifugation method [9]. Approximately $10 \mathrm{~g}$ of treated sample was immersed in deionized water and centrifuged at 1300 G. The centrifuged sample was accurately weighed and then dried again for about $18 \mathrm{~h}$ at 100 ${ }^{\circ} \mathrm{C}$ and reweighed. The water retention value was calculated using equation,

\section{$W R(\%)=100 \times$ Centrifuged weight - Dried weight/dried sample}

The WR (45\%) was calculated by sample of particle size $200 \mu \mathrm{m}$ and maximum WR value (64\%) was detected for thermally treated sample of same particle size. Therefore this sample was selected for adsorption of metal ions; where RW may increase because of interaction of these metal ions with different groups of activated sample. Therefore, the adsorption percent was increased up to more than $90 \%$.

\section{Effect of sorbent particle size on percent sorption}

The effect of sorbent particle size on $\%$ sorption was used to determine the adsorption potential of various metal ions, e.g. $\mathrm{Pb}, \mathrm{Ni}$ and $\mathrm{Co}$ [Fig. 6]. Three different sized samples, e.g. 50, 100 and $200 \mu \mathrm{m}$ were used for this purpose. The maximum sorption potential was found for particle size of $200 \mu \mathrm{m}$. Therefore, further studies were conducted using the sorbent of particle size 200 $\mu \mathrm{m}$. This increase in sorption potential can be attributed to increase in surface area (Fig. 6).

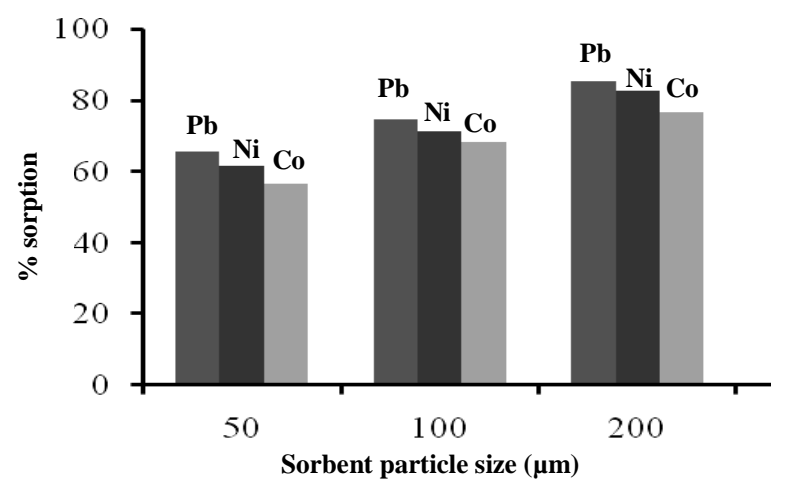

Figure 6. Effect of sorbent size on sorption 


\section{Effect of chemical and thermal treatment on sorption}

The effect of thermal and chemical activation on the efficiency of activated TT is shown in Fig.7.The sorption capacity was increased to $25 \%$ in TATT and $54 \%$ in CATT. This increase was due to increase in pore volume and surface area of sample that ultimately increased the sorption potential.

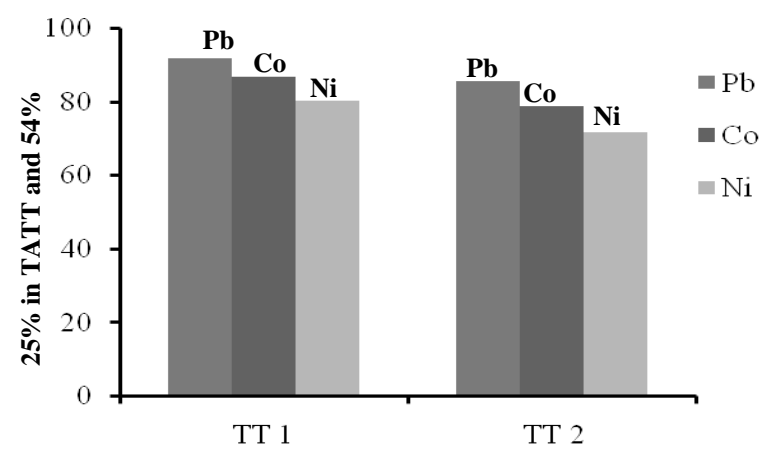

Figure 7. Effect of chemical \& thermal treatment on sorption

\section{Effect of pH on \% sorption}

The $\mathrm{pH}$ has a vital role on sorption of metal ions in the sorption process. The $\mathrm{pH}$ range of 1-10 was elaborated to study its effect on the sorption of $\mathrm{Pb}, \mathrm{Co}$ and $\mathrm{Ni}$ at shaking time $20 \mathrm{~min}$ 100 at rpm shaking speed. Studies were carried out by taking $0.5 \mathrm{~g}$ of sorbent in solution of metal ion with concentration of $12 \mathrm{ppm}$. The sorption potential was increased by increasing the $\mathrm{pH}$ up to 6 and decreased slightly after $\mathrm{pH} 6$ and then became constant (Fig.8).Therefore $\mathrm{pH} 6$ was considered to be optimum condition for maximum sorption.

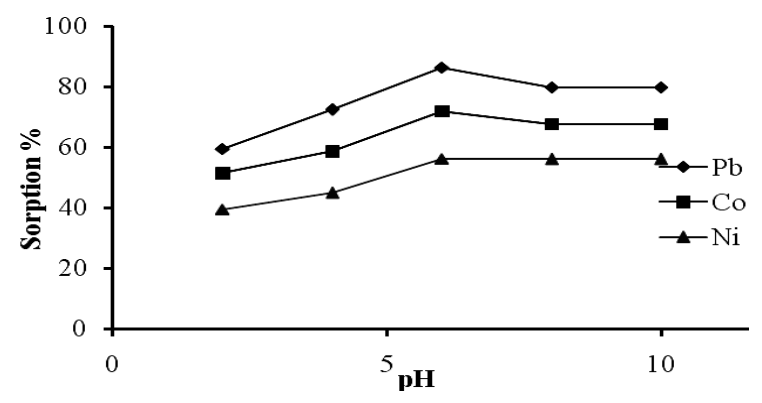

Figure 8. Effect of pH on \% sorption

\section{Effect of contact time on \% sorption}

It was seen that the rate of sorption was increased by increasing the contact time until the equilibrium was achieved. Initially a rapid increase in sorption shows extra cellular binding, no further increase indicates the possibility of monolayer coverage by metal ions on the surface of adsorbent [10]. By keeping the same conditions as for $\mathrm{pH}$ study, effect of contact time (5-40 min) was noted (Fig. 9) and for the maximal sorption of metal ions 20 min were found to be optimal. The maximum sorption of $\mathrm{Pb}, \mathrm{Co}$ and $\mathrm{Ni}$ ions observed was $89.45 \%, 82.47 \%$ and $75.85 \%$ respectively.

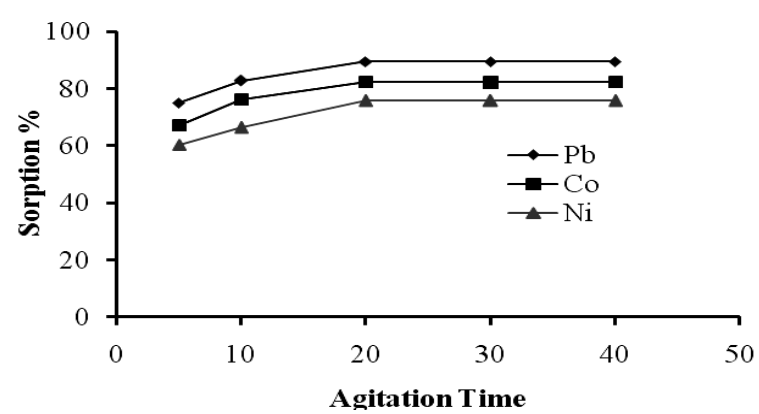

Figure 9. Effect of contact time on sorption

\section{Effect of shaking speed on \% sorption}

The sample material was shaken in order to enhance the interaction between the adsorption site of bio-sorbent and metal ions in the solution. By taking the sample under same condition, effect of shaking speed from 25-200 rpm was noted (Fig.10) and sorption was increased by increasing shaking speed and became maximum at $100 \mathrm{rpm}$. It was found that by increasing the shaking speed, the turbulence increases which in turn increases the metal adsorption ability.

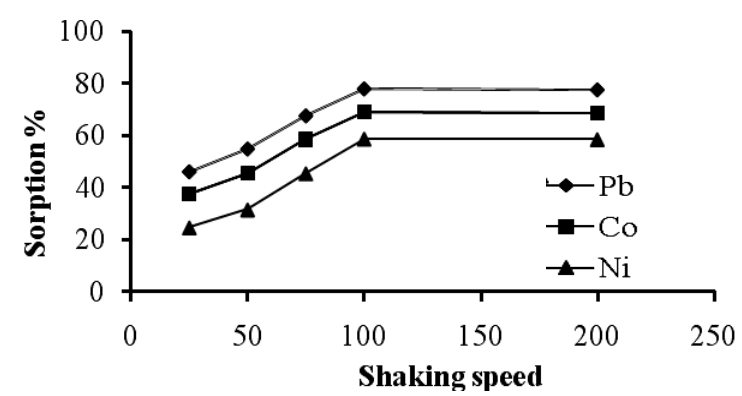

Figure 10. Effect of shaking speed on sorption 


\section{Effect of sorbent dose on \% sorption}

The effect of adsorbent dosage on adsorption of metal ions was studied using different doses in the range, $0.1-0.9 \mathrm{~g} / 100 \mathrm{~mL}$ (Fig. 11). The metal ion concentration in each case was recorded and it was found that adsorption efficiency is highly dependent on quantity of adsorbent added. Maximum removal of ions was recorded at dose $0.5 \mathrm{~g}$ and it was expected that as the concentration of adsorbent was increased, more active sites became available for metal ions uptake. Similar bio-sorbent dose behavior for all metal ions for adsorption was observed on various adsorbents. At higher adsorbent dosage efficiency was decreased, which can be explained by the partial aggregation of adsorbent that results in the decrease in an effective surface area hence lower metal ions uptake [11]. Therefore, the optimum dosage was selected as $0.5 \mathrm{~g}$.

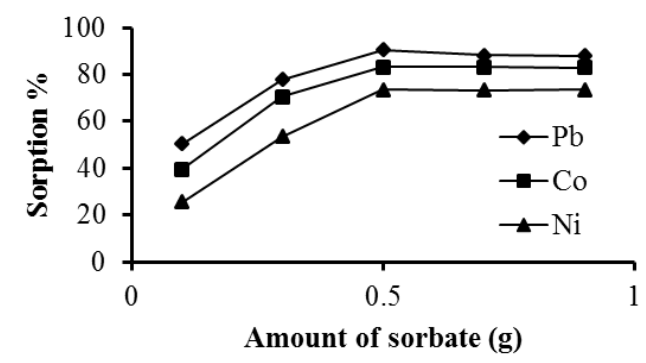

Figure 11. Effect of sorbent concentration on sorption \%

\section{Biosorption isotherms}

The bio-sorption process is evaluated by the analysis of equilibrium data. The sorption isotherms obtained from equilibrium indicate relationship between the sorbate and its amount accumulated on the sorbent surface. Freundlich and Langmuir bio-sorption process was evaluated first time by Dubinin-Radushkevich models.

\section{Freundlich isotherm}

The Freundlich isotherm is expressed in eq-1

Log Cads $=\log \mathrm{Cm}+1 / \mathrm{n} \log \mathrm{Ce}$

(eq-1)
Where, adsorption capacity and intensity is represented by constant parameters $\mathrm{Cm}$ and $\mathrm{n}$. A plot of $\log \mathrm{C}_{\mathrm{ads}}$ and $\log \mathrm{Ce}$ gives a straight line (Fig. 12). From this plot log $\mathrm{Cm}$ can be deduced from intercept however, value of $\mathrm{n}$ can be obtained from the slope. The energies and distribution sites are assumed as exponential and the surface of biomass is considered as heterogeneous in this isotherm [12].

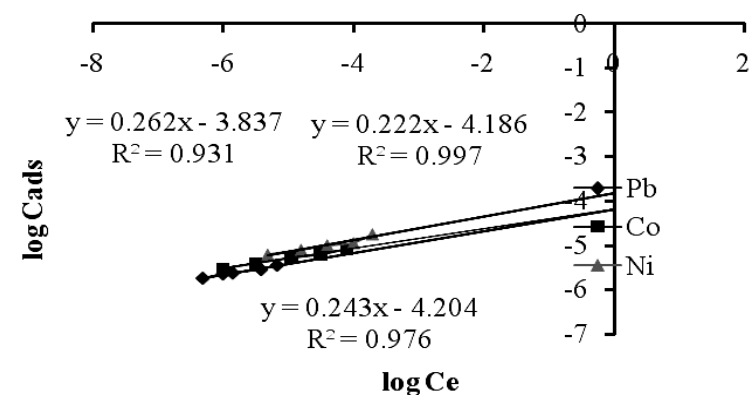

Figure 12. Freundlich plot for $\mathrm{Pb}$, $\mathrm{Co}$ and $\mathrm{Ni}$, TT $=0.5 \mathrm{~g},[\mathrm{~Pb}]$ $=0.02-0.01 \times 10^{-4} \mathrm{M},[\mathrm{Co}]=0.03-0.87 \times 10^{-4} \mathrm{M},[\mathrm{Ni}]=0.11-1.02 \times$ $10^{-4} \mathrm{M}$, Agitation time $=20 \mathrm{~min}$, Agitation speed $=100 \mathrm{rpm}, \mathrm{T}=$ $25^{\circ} \mathrm{C}$.

In the plot $\log \mathrm{Ce}$ versus $\log \mathrm{Cads}$ for $\mathrm{Pb}$, $\mathrm{Co}$ and $\mathrm{Ni}$ a straight line is shown in Fig. 15. The values of $1 / \mathrm{n}$ were found to be $0.24,0.22$ and 0.26 for $\mathrm{Pb}, \mathrm{Co}$ and $\mathrm{Ni}$ respectively from slope of the straight line. These values being $<1$ indicate that better sorption at a low concentration of sorbate while values of $\mathrm{Cm}$ were deduced from intercept are shown in Table 3.

Table 3. Freundlich constant for $\mathrm{Pb}, \mathrm{Co}$, and $\mathrm{Ni}$.

\begin{tabular}{c|c|c|c}
\hline \multicolumn{4}{c}{ Freundlich Isotherm Constants } \\
\hline Sorbate & $\boldsymbol{C m}\left(\boldsymbol{m}\right.$ mol $\left.^{-1}\right)$ & $\boldsymbol{R}^{\mathbf{1}}$ & $\boldsymbol{n}$ \\
\hline $\mathrm{Pb}(\mathrm{II})$ & 0.0624 & 0.976 & 4.1087 \\
$\mathrm{Co}(\mathrm{II})$ & 0.0651 & 0.997 & 4.2042 \\
$\mathrm{Ni}(\mathrm{II})$ & 0.1383 & 0.925 & 3.8952 \\
\hline
\end{tabular}

\section{Langmuir isotherm}

Langmuir isotherm gives information about maximum adsorption in the form of single layer of the sorbate molecules on the surface of bio-sorbent. It gives an idea about the energy involved in the process of desorption and found to be constant showing that after attachment on the surface the site of the adsorbate is not changed 
[13]. The mathematical form of Langmuir isotherm is given in equation eq- 2

$$
\frac{\mathrm{C}_{\mathrm{e}}}{\mathrm{q}_{\mathrm{e}}}=\frac{1}{\mathrm{Q}_{\mathrm{o}} \mathrm{b}}+\frac{1}{\mathrm{Q}_{\mathrm{o}}} \mathrm{C}_{\mathrm{e}}
$$

This is the linear form of equation. In this equation metal ions attached to the surface $(\mathrm{mg} / \mathrm{g})$ are expressed by $q e\left(\mathrm{C}_{\mathrm{ads}}\right)$, and metal ions concentration $\left(\mathrm{mgL}^{-1}\right)$ at equilibrium is given by Ce, $Q_{o}$ and $b$ are the constants which express the maximum capacity of absorbance and energy. A plot of Ce/qe and $\mathrm{Ce}$ gives a straight line at a given temperature (Fig.13). The $\mathrm{R}_{\mathrm{L}}$ an equilibrium parameter is basically dimensionless quantity explained by eq-3 is an important property of the isotherm.

$$
\mathrm{R}_{\mathrm{L}}=\frac{1}{\left(1+\mathrm{bC}_{\mathrm{o}}\right)}
$$

The favorability of isotherm can be deduced from $\mathrm{R}$ in the way as, if $(R>1)$ the type of isotherm is unfavorable, if $(R=0) \%$ is linear, it is favorable if $(0<R<1)$ and is irreversible if $(R=0)$ [14]. Langmuir considered sorption process as a chemical phenomenon [14].

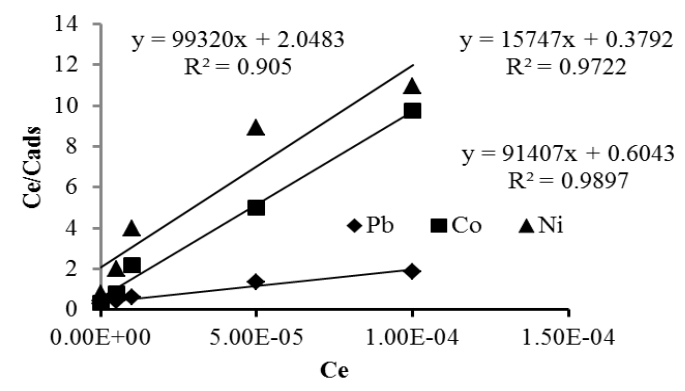

Figure 13. Langmuir plots for $\mathrm{Pb}$, $\mathrm{Co}$ and $\mathrm{Ni}$, $\mathrm{TT}=0.5 \mathrm{~g}, \mathrm{~Pb}=$ 0.02-0.01 $\times 10^{-4} \mathrm{M}, \mathrm{Co}=0.03-0.87 \times 10^{-4} \mathrm{M}, \mathrm{Ni}=0.11-1.02 \times 10^{-4} \mathrm{M}$, time $=20 \mathrm{~min}$, speed $=100 \mathrm{rpm}, \mathrm{T}=25^{\circ} \mathrm{C}$

The plots of Log Ce/Cads versus Ce for $\mathrm{Pb}, \mathrm{Co}$ and $\mathrm{Ni}$ are shown in fig 4.13. These plots gave straight lines and the values of various parameters deduced from graph are tabulated in Table 4. These values show that the bio-sorption process is well obeyed by Langmuir model. The values of $\mathrm{R}_{\mathrm{L}}$ are ranged between $0.07-0.25$, 0.050.56 and $0.11-0.70$ for $\mathrm{Pb}, \mathrm{Co}$ and $\mathrm{Ni}$, respectively.
These values fulfill the criteria of $(0<R<1)$, which indicates that TT is well suitable for the biosorption of divalent cations like $\mathrm{Pb}, \mathrm{Co}$ and $\mathrm{Ni}$. The Langmuir model also suggests that each sorbate ion is confined to a specific sorbent site which cannot interact and move across the neighboring molecules [15].

Table 4. Langmuir parameters for $\mathrm{Pb}, \mathrm{Co}$ and $\mathrm{Ni}$.

\begin{tabular}{c|c|c|c}
\hline \multicolumn{4}{c}{ Langmuir Isotherms Constants } \\
\hline Sorbate & $\boldsymbol{C}_{\boldsymbol{m}}\left(\boldsymbol{m ~ m o l ~}^{-1}\right)$ & $\boldsymbol{R}^{2}$ & $\boldsymbol{n}$ \\
\hline $\mathrm{Pb}(\mathrm{II})$ & 0.038096 & 0.983 & 1280313.142 \\
$\mathrm{Co}(\mathrm{II})$ & 0.008424 & 0.987 & 191904.9126 \\
$\mathrm{Ni}(\mathrm{II})$ & 0.018499 & 0.918 & 36466.58895 \\
\hline
\end{tabular}

\section{Dubinin-radushkevich isotherm}

D-R isotherm was used to evaluate equilibrium data from equation (eq-4).

Ln $\mathrm{C}_{\mathrm{ads}}=\ln \mathrm{X}_{\mathrm{m}}-\mathrm{BE}_{2}$

Where $C_{a d s}$ and $X_{m}$ are sorbed concentration and maximum sorption capacity at the sorbent surface and $\mathrm{B}$ is a constant related to sorption energy and $\mathrm{E}$ is Polanyi potential (eq-5).

$\mathrm{E}=\mathrm{RT} \ln \left(1+1 / \mathrm{C}_{\mathrm{e}}\right)$

If a straight line is obtained by plotting $\ln$ Cads against $\mathrm{E}_{2}$ it is considered as D-R isotherm. The slope gives the value of $B$ while values of $X_{m}$ can be deduced from intercept. The D-R isotherm model finds good application as being very simple its applicability in the concentration ranges from trace to saturated solutions. $\mathrm{E}$ is considered as Polanyi potential required to remove ions from sorption space. The volume where sorption takes place near to sorbent surface is fixed according to $\mathrm{D}-\mathrm{R}$ isotherm. If value of $\mathrm{E}$ falls in the range of 8$16 \mathrm{KJ} / \mathrm{mol}$, the sorption can be considered as ion exchange process, if $\mathrm{E}<16 \mathrm{KJ} / \mathrm{mol}$ then it might be due to contribution of physical forces and if $E>16$ $\mathrm{KJ} / \mathrm{mol}$ then it can be considered as chemical process. The straight line in the plot of $\ln$ Cads versus $E_{2}$ indicates that $D-R$ isotherm is well obeyed by all concentrations of $\mathrm{Pb}, \mathrm{Co}$ and $\mathrm{Ni}$ (Fig. 14). The slope and intercept of the straight line gives the values of $\mathrm{B}$ and $\mathrm{X}_{\mathrm{m}}$, which are given 
in Table 5. The sorption energy values of $\mathrm{E}$ were found to be $18.13,17.82$ and $16.22\left(\mathrm{KJ} \mathrm{mol}^{-1}\right)$ for $\mathrm{Pb}, \mathrm{Co}$ and $\mathrm{Ni}$ respectively showing sorption as a chemical process.

$\mathrm{E}=1 / \sqrt{2} \beta$

$(\mathrm{eq}-6)$

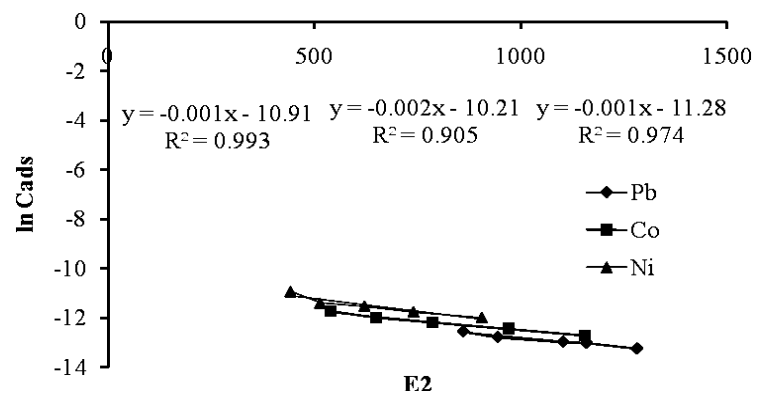

Figure 14. D-R sorption isotherms of $\mathrm{Pb}$, Co and Ni, TT $=0.5 \mathrm{~g}$, $\mathrm{Pb}=$ 0.02-0.01 $\times 10^{-4} \mathrm{M}, \mathrm{Co}=0.03-0.87 \times 10^{-4} \mathrm{M}, \mathrm{Ni}=0.11-1.02 \times$ $10^{-4} \mathrm{M}$, shaking constant time $=20 \mathrm{~min}$, shaking speed $=100 \mathrm{rpm}$, $\mathbf{T}=25^{\circ} \mathrm{C}$

Table 5. D-R isotherm for $\mathrm{Pb}, \mathrm{Co}$ and Ni on TT.

\begin{tabular}{c|c|c|c}
\hline \multirow{2}{*}{ Sorbate } & \multicolumn{3}{|c}{ D-R Isotherm } \\
\cline { 2 - 4 } & $\boldsymbol{X}_{\boldsymbol{m}}{\left.\boldsymbol{m ~} \text { mol g }^{-1}\right)}^{2}$ & $\boldsymbol{R}^{2}$ & $\boldsymbol{B}$ \\
\hline $\mathrm{Pb}(\mathrm{II})$ & 0.01259 & 0.974 & 0.0015 \\
$\mathrm{Co}(\mathrm{II})$ & 0.01819 & 0.993 & 0.0016 \\
$\mathrm{Ni}(\mathrm{II})$ & 0.0366 & 0.905 & 0.0019 \\
\hline
\end{tabular}

\section{Morris-Weber isotherm}

M-W model explains intra-particle diffusion sorption process. It is expressed in equation as

$\mathrm{q}_{\mathrm{t}}=\mathrm{R}_{\mathrm{id}} \cdot \mathrm{t}^{1 / 2}$

Where qt is referred as concentration of sorbed ions $\left(\mathrm{m} \mathrm{mol} / \mathrm{g}\right.$ ) against time $\mathrm{t} . \mathrm{R}_{\mathrm{id}}$ is the intra-particle diffusion rate constant. Sorption mechanism can be predicted by this model for TT by plotting $q t$ verses $t_{1 / 2}$. In case of a straight line obtained passing through the origin then sorption mechanism can be considered as the diffusion process. The value of $\mathrm{R}_{\mathrm{id}}$ can be deduced from the slope of the straight line. The results of $\mathrm{M}-\mathrm{W}$ isotherm are given in Fig.15 and Table 6. Since, the straight line is not passing through origin suggesting that diffusion is not only rate limiting step for the bio-sorption of $\mathrm{Pb}, \mathrm{Co}$ and $\mathrm{Ni}$ [16].
Table 6. Morris-Weber constant for $\mathrm{Pb}, \mathrm{Co}$ and $\mathrm{Ni}$.

\begin{tabular}{lcc}
\hline Sorbate & \multicolumn{2}{c}{ M-W Isotherms } \\
\cline { 2 - 3 } & $\boldsymbol{R}_{\text {id }}$ & $\boldsymbol{R}^{\mathbf{2}}$ \\
\hline $\mathrm{Pb}(\mathrm{II})$ & 0.410388 & 0.758 \\
$\mathrm{Co}(\mathrm{II})$ & 3.260176 & 0.798 \\
$\mathrm{Ni}(\mathrm{II})$ & 10.66554 & 0.803 \\
\hline
\end{tabular}

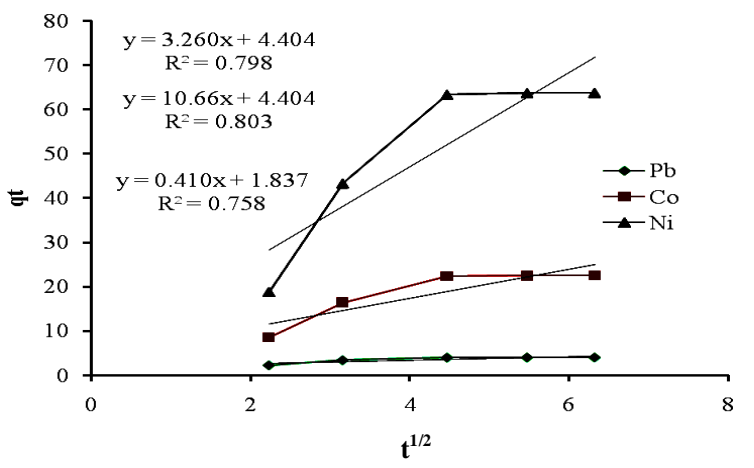

Figure 15. Morris-Weber isotherms for $\mathrm{Pb}, \mathrm{Co}$ and $\mathrm{Ni}, \mathrm{Pb}$ $=0.006 \times 10^{-4}, \mathrm{Co}=0.03 \times 10^{-4}, \mathrm{Ni}=1.11 \times 10^{-4} \mathrm{~mol} \mathrm{~L}^{-1}, \mathrm{TT}=$ $0.5, \mathrm{pH}=6, \mathrm{~T}=25^{\circ} \mathrm{C}$

\section{Conclusion}

This paper reports that the bio-sorbent potential of TT for removing the heavy metals from aqueous media. The bio-sorption capacity of TT was evaluated considering several effects, e.g. dose rate, contact time, $\mathrm{pH}$, speed of shaking, sorbent size and chemical and thermal treatment. FT-IR spectroscopy revealed the presence of various functional groups present on bio-sorbent surface and SEM revealed the surface morphological changes of bio-sorbent. It was concluded from this study that TT can act as biosorbent and can be used for waste water treatment at industrial level to remove the toxic metal ions.

\section{References}

1. W. J. Weber, Wiley Interscience, New York., (1972).

2. C. Chen and J. L. Wang, Environ. Sci. Technol., 27 (2006) 2261. https://www.ncbi.nlm.nih.gov/pubmed/1732 6437

3. M. Singanan. Sci. Asia, 37 (2011) 115. https://doi.org/10.2306/scienceasia15131874.2011.37.115

4. W. S. Wan Ngah and M. A. K. M. Hanafiah. A review. Bioresource Technol., 99 (2008), 
3935.https://doi.org/10.1016/j.biortech.2007. 06.011

5. A. Kapoor and T. Viraraghavan, Bioresource Technol., 53 (1995) 195. http://dx.doi.org/10.1016/09608524(95)80002-9

6. Q. Yu, J. T. Matheickal, P. Yin and P. Kaewsarn, Water Res., 33 (1999) 1534. https://doi.org/10.1016/S00431354(98)00363-7

7. Morton and J W S Hearle, in "Physical Properties of Textile Fibres", chapter 10, 3rd edition, The Textile Institute (1993)

8. O. Raize, Y. Argaman and S.Yannai, Biotechnol. Bioeng., 4 (2004) 451. https://doi.org/10.1002/bit.20136

9. Giora, R. and Yotam, G. (2009). Patent Application Nos. WO/2009/053972 B01J20/20; B01J20/32; B01J20/34; B01J39/24; B01J41/18, C02F1/28.
10. P. M. Pimentel, M. A. F. Melo, D. M. A. Melo, A. L. C. Assunção, D. M. Henrique, C. N. Silva Jr and G. González, Fuel Process. Tech., 89 (2008) 62. https://doi.org/10.1016/j.fuproc.2007.07.003

11. P. E. Aikpokpodion and R. R. Ipinmoroti, American-Eurasian, J. Toxicol. Sci., 2 (2010) 72. https://www.idosi.org/aejts/2(2)10/2.pdf

12. C. K. Jain, hydrolog. Sci. J., 46 (2001) 419. http://dx.doi.org/10.1080/0262666010949283 6

13. H. Freundlich and W. Heller, J. Am. Chem. Soc., 61 (1939) 2228. https://doi.org/10.1021/ja01877a071

14. Z. R. Holan, B. Volesky and I. Prasetyo, Biotechnol. Bioeng., 41(1993) 819. https://doi.org/10.1002/bit.260410808

15. H. A. Omar, A. S. Abdel-Razek and M. S.Sayed, Nature and Science, 8 (2010) 214.

16. H. J. Halil, Hazardous materials B, 97 (2002) 49. 